\title{
Of Hospitals, Doctors, GOVERnMENT, PAPERWORK and WAITING TIMES in EQUATORIAL AFRICA, 1914
}

... Our hospital is splendidly situated. Upstream and downstream, from places hundreds of kilometres away on the Ogowe and its tributaries, sick people are brought here, and the fact that those who bring them can be lodged here is a further encouragement to come in great numbers. And there is yet another attraction: the fact that I am always at home, unless - and this has happened only on two or three times so far - I have to go to some other mission station to treat a missionary who is ill, or some member of his family. Thus the native who has undertaken the trouble and the expense of the journey here from a distance, is sure of seeing me. That is the great advantage which the independent doctor has over one appointed by the Government. The latter is ordered now here, now there, by the authorities, or has to spend a long time with a military column on the march. "And that you have not got to waste so much time on correspondence, reports, and statistics, as we have to, is also an advantage, the reality of which you

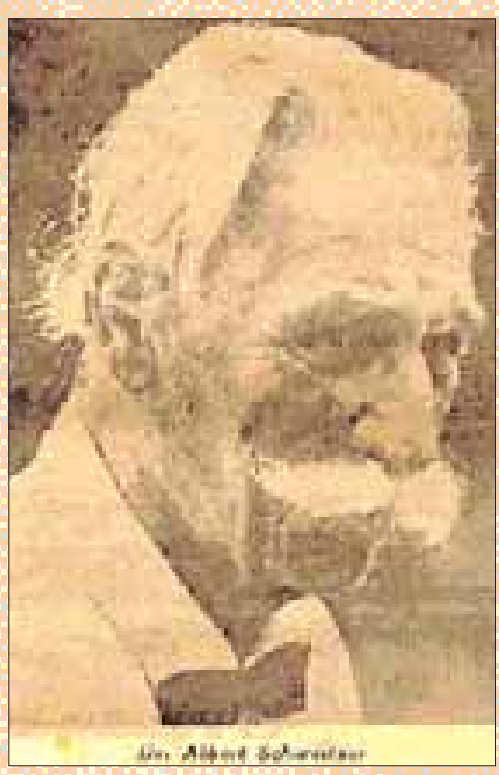

have not yet grasped," said an army doctor not long ago, during a short chat with me on his way past.

In a district where sleeping sickness has to be treated, its diagnosis is a terribly complicated business because the significance of every attack of fever, of ever persistent head-ache, of every prolonged attack of sleeplessness, and of all rheumatic pains must be gauged with the help of the microscope. Moreover, this examination of the blood is, unfortunately, by no means simple, but takes a great deal of time, for it is only very seldom that these pale, thin parasites, about one eighteen-thousandth
(1/18000) of a millimetre long, are to be found in any considerable number in the blood. So far I have only examined one case in which three or four were to be seen together. Even when the disease is certainly present one can, as a rule, examine several drops of blood one after another before discovering a single trypanosome, and to scrutinize each drop properly needs at least ten minutes. I may, therefore, spend an hour over the blood of a suspected victim, examining four or five drops without finding anything, and even then have no right to say there is no disease; there is still a long and tedious testing process which must be applied. This consists in taking ten cubic centimetres of blood from a vein in one of the sufferer's arms, and keeping it revolving centrifugally for an hour according to certain prescribed rules, at the same time pouring off at intervals the outer rings of blood. The trypanosomes are expected to have collected into the last few drops, and these are put under the microscope; but even if there is again a negative result, it is not safe to say that the disease is not present. If there are no trypanosomes to-day, I may find them ten days hence, and if I have discovered some to-day, there may be none in three days' time and for a considerable period after that. ...

If, then, I wish to treat such patients conscientiously, a couple of them together can tie me for a whole morning to the microscope, while outside there are sitting a score of sick people who want to be seen before dinner-time! There are also surgical patients whose dressings must be renewed; water must be distilled, and medicines prepared; sores must be cleansed, and there are teeth to be drawn! With this continual drive, and the impatience of the waiting sick, I often get so worried and nervous that I hardly know where I am or what I am doing.

Albert Schweitzer describing the scene at his hospital in French Equatorial Africa, 1914. From his book On the Edge of the Primeval Forest. London: Adam and Charles Black 1922. 